\title{
Soluble E-cadherin is a valid prognostic marker in gastric carcinoma
}

A O O Chan, S K Lam, K M Chu, C M Lam, E Kwok, S Y Leung, S T Yuen, S Y K Law, W M Hui, K C Lai, C Y Wong, H C Hu, C L Lai, J Wong
Department of Medicine, University of Hong Kong, Queen Mary Hospital, Hong Kong

A O O Chan

S K Lam

E Kwok

W M Hui

K C Lai

C Y Wong

$\mathrm{H} \mathrm{C} \mathrm{Hu}$

C L Lai

Department of

Surgery, University of Hong Kong, Queen

Mary Hospital, Hong

Kong

K M Chu

C M Lam

S Y K Law

J Wong

Department of Pathology, University of Hong Kong, Queen Mary Hospital, Hong

Kong

S Y Leung

$S$ T Yuen

Correspondence to: Professor S K Lam, Department of Medicine, University of Hong Kong,

Queen Mary Hospital,

Pokfulam Road, Hong Kong hrmelsk@hku.hk

Accepted for publication 14 November 2000

\begin{abstract}
Background-Gastric cancer remains a major cause of cancer mortality globally but no good prognostic tumour marker is available. Soluble fragment of E-cadherin protein has been reported to increase in the sera of patients with cancer and recently was found to be elevated in $67 \%$ of patients with gastric cancer.

Aims-To investigate if serum soluble $E$-cadherin is a valid prognostic marker in gastric cancer.
\end{abstract}

Methods-Concentrations of soluble E-cadherin from 116 patients with histologically confirmed gastric adenocarinoma and 40 healthy subjects were measured using an immunoenzymometric method with a commercially available sandwich ELISA kit based on monoclonal antibodies.

Results-The logarithm of the means of soluble E-cadherin concentration was significantly higher in patients with gastric cancers (mean 3.85 (SD 0.28)) than in healthy subjects $(3.71(0.18))(p=0.001)$, and in palliative/conservatively treated cancers $(3.91(0.35))$ than in operable cancers $(3.78(0.19))(p=0.015)$. The logarithm of the concentrations correlated with tumour size $(p=0.032)$ and carcinoembryonic antigen concentrations $(p=0.001)$. The cut off value calculated from discriminant analysis on operability and inoperability/palliative treatment was 7025 ng/ml. Soluble E-cadherin concentrations higher than this cut off value predicted tumour (T4) depth invasion $(p=0.020$, confidence interval (CI) 1.008 1.668) and palliative/conservative treatment $(p=0.023$, CI 1.038-2.514). In contrast, the relative risks for lymph node (N2) metastasis, distant metastasis, and stage III/IV disease were $1.41,1.33$, and 1.55 respectively, despite not reaching statistical significance.

Conclusion-Serum soluble E-cadherin is a potential valid prognostic marker for gastric cancer. A high concentration predicts palliative/conservative treatment and $\mathrm{T} 4$ invasion.

(Gut 2001;48:808-811)

Keywords: E-cadherin; gastric cancer; tumour marker

Gastric cancer remains the second major cause of cancer related deaths in the world. ${ }^{1}$ However, there is currently no satisfactory tumour marker for diagnosis or monitoring disease progress. The most frequently used tumour markers in gastric cancer are carcinoembryonic antigen (CEA) and CA19-9, but only a modest proportion of patients have elevated levels of these markers.

The cadherins are a major class of adhesion molecules which play an important role in the homotypic cell-cell adhesion and hence cancer cell metastasis and invasion. E-cadherin is a member of the cadherin family which is expressed in all epithelial cells. The role of E-cadherin in metastasis and invasion is evidenced by the fact that the invasiveness of epithelial tumour cell lines was inhibited in vitro by transfection and expression of E-cadherin cDNA, and induced again by exposure to anti-E-cadherin monoclonal antibodies. ${ }^{2-4}$ Under expression of E-cadherin molecule has been found in various malignancies and has potential value as a prognostic marker. ${ }^{5}$

Serum soluble E-cadherin is the degradation product of the cellular E-cadherin molecule. It is found in the circulation of normal individuals but is particularly elevated in patients with malignancies. Serum soluble E-cadherin has been shown to be a potentially valuable prognostic marker for carcinoma of the bladder. ${ }^{6}$ However, its prognostic value has not been proved in colorectal cancer, ${ }^{7}$ and its value in gastric cancer is controversial. Velikova and colleagues ${ }^{8}$ were unable to show a significant difference in serum soluble E-cadherin between patients with gastric cancer and normal subjects, while Gofuku and colleagues ${ }^{9}$ showed that concentrations were significantly elevated in $67 \%$ of patients. The aim of the present study was to investigate the value of serum soluble E-cadherin as a prognostic marker in patients with gastric cancer.

\section{Methods}

PATIENT SELECTION

All patients admitted from 1 January 1997 to 30 September 1998 to the Departments of Medicine and Surgery, Queen Mary Hospital, with histologically proved gastric carcinoma, including both operable and inoperable tumours, were recruited. The sera of 125 patients were collected after gastric cancer was confirmed histologically and before operation or initiation of chemotherapy. Nine patients were excluded from the present analysis because two were non-Chinese, one had serum collection after tumour debulking, one had another

Abbreviations used in this paper: CEA, carcinoembryonic antigen. 
synchronous tumour, and five had coincidental liver cirrhosis. Therefore, the total number of patients included in the analysis was 116 . A group of 40 healthy subjects was recruited as controls.

\section{PATIENT ASSESSMENT AND DEFINITIONS OF} TREATMENTS

After gastric cancer was confirmed histologically by endoscopic biopsy, the extent of disease was assessed by chest $x$ ray, endoscopic ultrasound, and computer tomography or ultrasound of the abdomen. Curative resection was defined as UICC R0 resection. Palliative treatment included UICC R1 or R2 resection, gastrojejunostomy, or palliative chemotherapy. Conservative treatment referred to those patients receiving symptomatic support only.

STAGING AND CLASSIFICATION OF GASTRIC CANCER

Tumour was staged according to the criteria of the Japanese Research Society for Gastric Cancer ${ }^{10}$ and classified histologically according to the WHO and Lauren's classification. ${ }^{11}$

ASSAY OF SOLUBLE E-CADHERIN

Venous blood samples were collected into plain tubes, allowed to clot, and within one hour of collection were centrifuged at $800 \mathrm{~g}$ for 10 minutes at $4^{\circ} \mathrm{C}$ to obtain serum. Serum was removed, aliquoted, and stored at $-70^{\circ} \mathrm{C}$ until assay. Concentrations of soluble E-cadherin were measured with a commercially available sandwich ELISA kit based on monoclonal antibodies (Zymed Laboratories Inc., South San Francisco, California, USA). All blood samples were measured by an investigator who was blinded to the clinical details and coded data sheet. Each sample was measured twice.

The assay method has been described previously. ${ }^{12}$ In brief, the first monoclonal antibody, HECD-1, was coated onto microtitre plate wells to create the solid phase. Non-specific binding was blocked by a blocking buffer. Serum samples from patients and standard solutions supplied were incubated in the microtitre plate wells. The second monoclonal antibody, SHE 13-1, labelled with peroxidase was added. During incubation, human E-cadherin molecule was trapped by the two monoclonal antibodies as a sandwich. The reaction between the peroxidase and substrate solution $\left(\mathrm{H}_{2} \mathrm{O}_{2}\right.$ and tetramethybenzidine) resulted in colour development with intensities proportional to the concentration of human E-cadherin present in the samples and standards. The colour developed was measured with the microtitre plate reader for measurement of absorbance at $450 \mathrm{~nm}$. Accurate sample concentrations of human E-cadherin were determined by comparing specific absorbances with those obtained from the standards plotted on a standard curve.

STATISTICAL METHODS

Data were collected and analysed using the Statistical Package for the Social Sciences. Logarithmic transformation was performed on soluble E-cadherin data for conversion to a normal distribution. Clinical and biochemical parameters of patients are expressed as mean (SD). Comparisons were performed using the independent sample Student's $t$ test and the $\chi^{2}$ test. Differences were considered significant when $\mathrm{p}<0.05$, and approaching statistical significance when $p<0.1$ and $\geqslant 0.05$. Cut off values of soluble E-cadherin concentration were calculated by discriminant analysis.

\section{Results}

There were 75 men and 41 women in the patient group with a mean age of 66 (14) years. There were 19 men and 21 women in the control group with a mean age of 31 (10) years. The sizes of the tumours measured from the pathological specimens obtained after resection ranged from $0.5 \mathrm{~cm}$ to $18 \mathrm{~cm}$ (mean 4.8 $(3.2) \mathrm{cm}$ ). Forty eight per cent of tumours were located in the gastric antrum. Of those with gastric resection specimen available for pathological examination, $61 \%$ were of the intestinal-type, $30 \%$ were the diffuse-type, and $9 \%$ were a mixed-type according to Lauren's classification. The percentage of patients with stage I, II, III, and IV disease were $12.6 \%$, $18.4 \%, 28.2 \%$, and $40.8 \%$, respectively. Therefore, most patients presented at advanced stages.

The means of the logarithm of soluble E-cadherin concentration in patients with gastric cancer were significantly higher than those of normal healthy subjects $(3.85(0.28) v 3.71$ $(0.18) ; p=0.001)$. In contrast, the means of the logarithm of soluble E-cadherin concentration in patients with T4 invasion, liver metastasis, distant metastasis, and stage III/IV disease were higher than the means of other tumour depth invasion, absence of liver metastasis, absence of distant metastasis, and stage I/II disease, respectively, with $\mathrm{p}$ values approaching statistical significance $(\mathrm{p}=0.057,0.067,0.082$, 0.086 , respectively). The logarithm of soluble E-cadherin concentration correlated with the size of the tumour $(p=0.032)$ and with the logarithm of CEA concentration $(p=0.001)$.

Fifty four patients underwent curative gastric resection while 43 patients received palliative treatment. Another 10 patients received conservative treatment only. Nine patients were excluded from further analysis of their treatment results because eight were operable but medically unfit and one committed suicide before receiving any treatment. The means of the logarithm of soluble E-cadherin concentrations in patients receiving palliative/ conservative treatment and those receiving curative resection were $3.91(0.35)$ and 3.78 $(0.19)$, respectively $(\mathrm{p}=0.015)$.

The cut off value for serum soluble E-cadherin of normal subjects and patients with gastric cancer was calculated as 5994 $\mathrm{ng} / \mathrm{ml} ; 27.5 \%$ of normal subjects and $51.7 \%$ of patients were above this cut off value. The cut off value for curative treatment and palliative/ conservative treatment was calculated as 7025 $\mathrm{ng} / \mathrm{ml}$. Concentrations higher than $7025 \mathrm{ng} / \mathrm{ml}$ were used to predict the relative risks of various poor prognostic factors (table 1). Patients with soluble E-cadherin concentrations above the 
Table 1 Prediction of relative risks of various prognostic factors using concentrations of soluble E-cadherin higher than the cut off value (> $7025 \mathrm{ng} / \mathrm{ml}$ )

\begin{tabular}{lllll}
\hline Factor & Category & $\begin{array}{l}\text { Relative } \\
\text { risk }\end{array}$ & $p$ Value & $\begin{array}{l}\text { Confidence } \\
\text { interval }\end{array}$ \\
\hline $\mathrm{T}$ & T4 $v$ T1 or T2 or T3 & 1.30 & $\mathbf{0 . 0 2 0}$ & $\mathbf{1 . 0 0 8 - 1 . 6 6 8}$ \\
$\mathrm{N}$ & N2 $v$ N0 or N1 & 1.41 & $0.064^{\star}$ & $0.944-2.118$ \\
$\mathrm{M}$ & M1 $v$ M0 & 1.33 & $0.073^{\star}$ & $0.954-1.859$ \\
Staging & Stage III or IV $v$ stage I or II & 1.55 & 0.164 & $0.82-2.913$ \\
Operability & Palliative/conservative $v$ operable & 1.62 & $\mathbf{0 . 0 2 3}$ & $\mathbf{1 . 0 3 8 - 2 . 5 1 4}$
\end{tabular}

$\mathrm{T}$, tumour; $\mathrm{N}$, lymph node; $\mathrm{M}$, metastasis.

$\mathrm{p}<0.05$ is considered statistically significant and is indicated by bold type; $\mathrm{p}<0.1$ but $>0.05$ is considered approaching statistical significance and is indicated by an asterisk.

cut off value were more likely to have T4 invasion $(p=0.020$, confidence interval (CI) 1.008$1.668)$ and palliative/conservative treatment $(\mathrm{p}=0.023$, CI $1.038-2.514)$. The relative risks of N2 metastasis, distant metastasis, and stage III/IV disease were 1.41, 1.33, and 1.55, respectively (NS).

\section{Discussion}

During carcinogenesis, tumour cells have to dissociate from one another before they can invade or metastasise. Therefore, adhesion molecules are expected to play an important role in carcinogenesis and especially metastasis. Decreased membranous expression of $\mathrm{E}$-cadherin molecules has been found in gastric cancer ${ }^{1314}$ and other malignancies such as colon, ${ }^{15}{ }^{16}$ pancreas,${ }^{17}$ oesophagus, ${ }^{18}$ liver,${ }^{19}$ prostate, ${ }^{20}$ bladder, ${ }^{2122}$ breast, ${ }^{23}{ }^{24}$ and head and neck tumours. ${ }^{25}$ Disruption of membranous expression of E-cadherin could be caused by disturbed polarisation of the cell, or mutations or partial deletions of the E-cadherin gene, ${ }^{26}$ resulting in a protein which is not transported to the cell membrane. Direct correlation between E-cadherin and grade of tumour differentiation has been observed in some tumours. ${ }^{20-22}$ In a multivariate retrospective study of 413 patients with gastric cancer, E-cadherin positive tumours had significantly better three and five year survival rates than E-cadherin negative tumours. ${ }^{27}$

Soluble E-cadherin, a $80 \mathrm{kDa}$ peptide, is considered to be the degradation product of the $120 \mathrm{kDa}$ intact E-cadherin generated by a $\mathrm{Ca}^{2+}$ ion dependent proteolytic action. ${ }^{28}{ }^{29}$ The peptide was found in the circulation of healthy subjects and was not dependent on age or sex. It was elevated in patients with gastric carcinoma and other malignancies. ${ }^{12}$ Increased serum soluble E-cadherin concentrations have also been found in pemphigoid or pemphigus skin conditions, ${ }^{30-32}$ and in multiorgan failure. ${ }^{33}$ As E-cadherin is expressed in all epithelial cells, any condition with rapid epithelial cell turnover may lead to an increase in its concentration. Therefore, patients with these conditions and those with chronic inflammatory diseases were excluded from our study. In addition, patients with cirrhosis were also excluded as we believe that in cirrhosis cell turnover is rapid and may result in higher levels of soluble E-cadherin. This has been confirmed in our unpublished data. However, it is also important to identify other conditions that may significantly affect soluble E-cadherin concentrations.
The present study confirmed the observation that concentrations of soluble E-cadherin in patients with gastric cancer were higher than those in healthy subjects. However, higher soluble E-cadherin concentrations were observed both in our healthy subjects and patients compared with those reported in the literature, with a mean value of $5616 \mathrm{ng} / \mathrm{ml}$ versus 2515 $\mathrm{ng} / \mathrm{ml}$ in healthy subjects, and $9344 \mathrm{ng} / \mathrm{ml}$ versus $4735 \mathrm{ng} / \mathrm{ml}$ in patients with gastric carcinoma. ${ }^{9}$ Only Chinese subjects were recruited to the study because we do not know if racial differences have any effect on soluble E-cadherin concentrations. Differences in biological behaviour in gastric cancer between Japan and the Western world have been suggested and may account for the observed differences in prognosis. ${ }^{34}$ Therefore, higher E-cadherin concentrations in our patients and normal controls could be due to racial differences. In addition, the fact that most of our patients had advanced disease may also explain in part the high concentrations of soluble E-cadherin. Consequently, each laboratory should have its own reference range.

Our results showed that soluble E-cadherin concentrations were elevated in patients receiving palliative/conservative treatment and were correlated with the size of the gastric tumour. Patients with soluble E-cadherin concentrations higher than the $7025 \mathrm{ng} / \mathrm{ml}$ cut off value were more likely to have non-curative resection, possibly due to $\mathrm{T} 4$ invasion. In addition, these patients were more likely to have stage III or IV disease, although this was not statistically significant. However, this observation was biased by the fact that a large number of patients with advanced disease were inoperable and therefore their diseases could not be staged thus rendering the results less significant. Tumour size, depth of tumour invasion, and operability are important prognostic factors in patients with gastric carcinoma. Tumour size has been reported as a simple prognostic indicator for gastric carcinoma. ${ }^{35}$ Soluble E-cadherin may originate from the rapid turnover of tumour cells. Therefore, the bigger the tumour size, the higher the soluble E-cadherin concentration. The increase in relative risk of metastases in patients with higher soluble E-cadherin concentrations reflected the role of E-cadherin as an "invasion suppressor molecule". ${ }^{36}$

Our data showed that serum soluble E-cadherin correlated with poor prognostic markers. High serum soluble E-cadherin predicted T4 invasion and palliative/conservative treatment. However, it was only elevated in a subgroup of patients. Therefore, further studies should aim at identifying the subgroup of gastric cancer patients who have elevated soluble E-cadherin concentrations, thereby increasing its sensitivity, comparing the prognostic value of soluble E-cadherin and conventional markers such as CEA in patients with gastric cancer, and also identifying other conditions that may affect soluble E-cadherin concentrations. In addition, prospective studies should also be carried out to investigate post-treatment soluble E-cadherin levels and 
their role in therapeutic monitoring in patients with gastric cancer.

Presented in part at the Digestive Disease Week, Orlando, USA, May 1999, and published in abstract form in Gastroenterology
1999;116:A388. The authors are indebted to Professor Bart 1999;116:A388. The authors are indebted to Professor Bart lic Health, Houston, for expert advice on statistical analysis.

1 Food, nutrition and the prevention of cancer: A global perspective. Washington, DC. World Cancer Research Fund and American Institute for Cancer Research, 1997:150.

2 Behrens J, Mareel MM, Van Roy FM, et al. Dissecting tumor cell invasion: epithelial cells acquire invasive properties after the loss of uvomorulin-mediated cell-cell adhesion. F Cell Biol 1989;108:2435-47.

3 Frixen UH, Behrens J, Sachs M, Eberle G, et al. E-cadherinmediated cell-cell adhesion prevents invasiveness of human carcinoma cells. $\mathcal{F}$ Cell Biol 1991;113:173-85.

4 Vleminckx K, Vakaet L Jr, Mareel M, et al. Genetic manipulation of E-cadherin expression by epithelial tumor cells reveals an invasion suppressor role. Cell 1991;66:107-19.

5 Takeichi M. Cadherins in cancer: implications for invasion and metastasis. Curr Opin Cell Biol 1993;5:806-11.

6 Griffiths TR, Brotherick I, Bishop RI, et al. Cell adhesion molecules in bladder cancer: soluble serum E-cadherin correlates with predictors of recurrence. Br f Cancer 1996; 74:579-84.

7 Velikova G, Banks RE, Gearing A, et al. Serum concentrations of soluble adhesion molecules in patients with colortions of soluble adhesion molecules in patie

8 Velikova G, Banks RE, Gearing A, et al. Circulating soluble adhesion molecules E-cadherin, E-selectin, intercellular adhesion molecule-1 (ICAM-1) and vascular cell adhesion molecule-1 (VCAM-1) in patients with gastric cancer. $\mathrm{Br} F$ Cancer 1997;76:1398-404.

9 Gofuku J, Shiozaki H, Doki Y, et al. Characterization of soluble E-cadherin as a disease marker in gastric cancer patients. Br f Cancer 1998;78:1095-101.

10 Nishi M, Omori Y, Miwa K, eds. Japanese Research Society for Gastric Cancer. Fapanese Classification of Gastric Carcinoma. Tokyo: Kanehara, 1995.

11 Lauren P. The two histological main types of gastric carcinoma: diffuse and so-called intestinal-type carcinoma. Acta Pathol Microbiol Scand 1965;64:31-49.

12 Katayama M, Hirai S, Kamihagi K, et al. Soluble E-cadherin fragments increased in circulation of cancer patients. $B r F$ Cancer 1994;69:580-5.

13 Shimoyama Y, Hirohashi S. Expression of E- and P-cadherin in gastric carcinomas. Cancer Res 1991;51: P-cadherin

14 Mayer B, Johnson JP, Leitl F, et al. E-cadherin expression in primary and metastatic gastric cancer: down-regulation correlates with cellular dedifferentiation and glandular disintegration. Cancer Res 1993;53:1690-5.

15 Dorudi S, Sheffield JP, Poulsom R, et al. E-cadherin expression in colorectal cancer. An immunocytochemical and in situ hybridization study. Am f Pathol 1993;142:981-6.

16 Gagliardi G, Kandemir O, Liu D, et al. Changes in E-cadherin immunoreactivity in the adenoma-carcinoma sequence of the large bowel. Virchows Arch 1995;426:14954.

17 Pignatelli M, Ansari TW, Gunter P, et al. Loss of membranous E-cadherin expression in pancreatic cancer: correlation with lymph node metastasis, high grade, and advanced stage. F Pathol 1994;174:243-8.
18 Jankowski JA, Newham PM, Kandemir O, et al. Differential expression of E-cadherin in normal, metaplastic and dysplastic oesophageal mucosa: a putative biomarker. Int $\mathcal{F}$ Oncol 1994;4:441-8.

19 Kozyraki R, Scoazec JY, Flejou JF, et al. Expression of cadherins and alpha-catenin in primary epithelial tumors of the liver. Gastroenterology 1996;110:1137-49.

20 Umbas R, Isaacs WB, Bringuier PP, et al. Decreased E-cadherin expression is associated with poor prognosis in patients with prostate cancer. Cancer Res 1994;54:3929-33.

21 Bringuier PP, Umbas R, Schaafsma HE, et al. Decreased E-cadherin immunoreactivity correlates with poor survival in patients with bladder tumors. Cancer Res 1993;53:32415.

22 Syrigos KN, Krausz T, Waxman J, et al. E-cadherin expression in bladder cancer using formalin-fixed, paraffinembedded tissues: correlation with histopathological grade, tumour stage and survival. Int 7 Cancer 1995;64:367-70.

23 Moll R, Mitze M, Frixen UH, et al. Differential loss of E-cadherin expression in infiltrating ductal and lobular breast carcinomas. Am f Pathol 1993;143:1731-42.

24 Siitonen SM, Kononen JT, Helin HJ, et al. Reduced $\mathrm{E}$-cadherin expression is associated with invasiveness and unfavorable prognosis in breast cancer. Am $\mathcal{F}$ Clin Pathol 1996;105:394-402.

25 Andrews NA, Jones AS, Helliwell TR, et al. Expression of the E-cadherin-catenin cell adhesion complex in primary squamous cell carcinomas of the head and neck and their nodal metastases. Br f Cancer 1997;75:1474-80.

26 Becker KF, Atkinson MJ, Reich U, et al. Exon skipping in the E-cadherin gene transcript in metastatic human gastric carcinomas. Hum Mol Genet 1993;2:803-4.

27 Gabbert HE, Mueller W, Schneiders A, et al. Prognostic value of E-cadherin expression in 413 gastric carcinomas. Int F Cancer 1996;69:184-9.

28 Wheelock MJ, Buck CA, Bechtol KB, et al. Soluble 80-kd fragment of cell-CAM 120/80 disrupts cell-cell adhesion. $\mathcal{7}$ Cell Biochem 1987;34:187-202.

29 Takeichi M. The cadherins: cell-cell adhesion molecules controlling animal morphogenesis. Development 1988;102: 639-55.

30 Furukawa F, Fujii K, Horiguchi Y, et al. Roles of E- and P-cadherin in the human skin. Microsc Res Tech 1997;38: 343-52.

31 Shirahama S, Furukawa F, Wakita H, et al. E- and $\mathrm{P}$-cadherin expression in tumor tissues and soluble E-cadherin levels in sera of patients with skin cancer. F Dermatol Sci 1996;13:30-6.

32 Matsuyoshi N, Tanaka T, Toda K, et al. Soluble E-cadherin: a novel cutaneous disease marker. Br F Dermatol 1995;132: $745-9$.

33 Pittard AJ, Banks RE, Galley HF, et al. Soluble E-cadherin concentrations in patients with systemic inflammatory response syndrome and multiorgan dysfunction syndrome. Br f Anaesth 1996;76:629-31.

34 Livingstone JI, Yasui W, Tahara E, et al. Are Japanese and European gastric cancer the same biological entity? An immunohistochemical study. Br f Cancer 1995;72:976-80.

35 Adachi Y, Oshiro T, Mori M, et al. Tumour size as a simple rognostic indicator for gastric carcinoma. Ann Surg Oncol 1997;4:137-40.

36 Birchmeier W, Behrens J. Cadherin expression in carcinomas: role in the formation of cell junctions and the prevention of invasiveness. Biochem Biophys Acta 1994; 1198: 11-26. 